\title{
TIEMPO DE ESPERA. EL CRONOTOPO DE TETRALOGÍA DE LAS CUATRO ESTACIONES DE LEONARDO PADURA
}

\author{
Bernat Garí Barceló \\ Universitat de Barcelona \\ Barcelona, España \\ bernatgari@ub.edu

\section{RESUMEN / ABSTRACT}

El objetivo de este artículo es reflexionar la supresión del tiempo lineal en Tetralogía de las Cuatro Estaciones de Leonardo Padura a la luz de nociones como 'cronotopo' y 'uróboros'. Las primeras novelas neopoliciales de Padura, reunidas en dicha tetralogía, no se ajustan a la secuencia cronológica arquetípica del policial clásico y la novela negra -el cronotopo de seguimiento-, sino que participan de una tensión entre la sucesión circular de la historia y el desencanto utópico de un detective que funda sus escasas esperanzas en el porvenir. La imbricación de dichos tiempos, bien trabajados narrativamente, permite trazar algunas líneas interpretativas desde las que será posible caracterizar el neopolicial de Padura.

Palabras clave: Padura, Bajtín, neopolicial, cronotopo, uróboros.

\section{WAITING TIME. THE CHRONOTOPE OF' TETRALOGY \\ OF THE FOUR SEASONS'BY LEONARDO PADURA}

The purpose of this article is to think about the suppression of linear time in 'Tetralogy of the Four Seasons' by Leonardo Padura, in the light of notions such as 'chronotope' and 'ouroboros'. The first of the neo-crime novels by Padura gathered in the above-mentioned tetralogy, are not adjusted to the archetypal, sequential chronological sequence of the classic crime and noir novel genre. On the contrary, they participate in the tension between the circular succession of history and the utopian disillusionment of a detective who pins his scant hopes on the future. The overlap of these times, in a skilfully worked narrative, allows the plotting of interpretative lines from which it will be possible to characterise the neo-crime style of Padura.

KEYWORDS: Padura, Bajtín, neo-crime genre, chronotope, ouroboros. 


\section{CUESTIONES PRELIMINARES. EL 'CRONOTOPO DE SEGUIMIENTO’ EN EL GÉNERO POLICIAL}

La tetralogía de Padura pertenece a una extraña familia de novelas que, como las describe Vargas Llosa en su tesis doctoral sobre García Márquez, se construyen como "episodios que se muerden la cola" (625), esto es, a partir de temas con variaciones que se bifurcan y giran sobre sí. La formulación 'urobórica' ${ }^{1}$ de dichos textos responde por lo general a una voluntad de repensar los marcos de la modernidad -o la "actitud de modernidad" (Foucault 8), cifrada, según Foucault, en el pensamiento kantiano-, interrogando su ley interior y con el propósito de desautomatizar o deconstruir la confianza ilustrada en el progreso y la constelación de categorías que la acompañan (sujeto, revolución, técnica, colonialismo, etc.). Se pretende desdramatizar, también, la historia hegeliana como sistema explicativo, como "negación de la negación" y marcha panlogicista del Espíritu hacia el Absoluto, que hallaría en Marx su formulación más tangible y radical $^{2}$. En el otro extremo, en un esquema cíclico, central en Padura, la lógica que acompaña el movimiento del tiempo no es el cambio, sino el reflejo, que automatiza el gesto, lo exacerba, lo reitera y lo subsume en la eternidad. De ahí que ese movimiento desactive las ficciones que acompañan la lectura hegeliana de lo moderno -historia, progreso, dominio, sujeto- que desfallecen según se alejan de su hábitat natural. Octavio Paz, en Los hijos del limo, sintetiza estas ideas: "para nosotros [los modernos] el tiempo es el portador del cambio, para ellos [los antiguos] es el agente que lo suprime" (28). Se deduce de ello que el pasado, dispositivo simbólico significante, dentro del sistema hegeliano, es acumulativo y degradativo, según se queman dialécticamente, en su dimensión panagonista, los periodos en contacto (Hegel 121-155); en cambio, en un paradigma cíclico, el pasado es un espacio móvil, lejano y cercano a la vez, cuyo encaje en la fuga lineal del tiempo resulta una cuestión problemática, si no quimérica.

El uróboros (del griego ovpoßópos), o el dragón que muerde su cola, encarna el cansancio de Sísifo y la fatalidad del regreso, y se inscribe en el interior de un paradigma cíclico en el que el pasado y el futuro son correlativos.

Disponemos, según Marx, de instrumentos óptimos para transformar revolucionariamente la realidad (Calinescu 32) o, dicho de otro modo, la revolución vehicula el progreso hacia su despliegue esencial, esto es, el final de la historia y la suspensión de la negatividad. 
Bajtín asocia las formas circulares o "urobóricas" al cronotopo bucólico e idílico-pastoril que es un importante estímulo en las sagas familiares (en los Buddenbrook de Thomas Mann, en Bilder aus der deutschen Vergangenheit de Freytag, en Cien años de soledad de Márquez, etc.), en la novela sentimental de corte rousseauniano, en la novela pastoril y en novelas regionales o de comarca. La sujeción del idilio a un tiempo remoto, inaccesible, confiere a este tipo de obras un carácter semicircular, abierto, signado por la repetición (Bajtín 361), en el que los límites entre pasado, presente y futuro se desdibujan en la evocación constante del origen. Para el autor, en cambio, que en su Teoría y estética de la novela apenas dedica unas escasas alusiones al género policial -y por su falta de especificidad parece que se remite por igual a la novela enigma y a la novela negra estadounidense ${ }^{3}-$, el relato de detectives reposa sobre el esquema de la novela griega de aventuras y costumbres. Su funcionamiento responde, por tanto, a una configuración más secuenciada en la que el conflicto, la huida, el encuentro y el descubrimiento vertebran el recorrido del héroe y adquieren significación cronotópica relevante para la interpretación del conjunto.

María Susana Ibáñez matiza que el género policial está sujeto a un "cronotopo de seguimiento" (120), en el que la persecución y el interrogatorio, de escasa relevancia en la novela bizantina o la novela de aventuras, desempeña un papel organizativo, sobre todo, en la novela negra estadounidense y en su reformulación neopolicial. Eso sí, no precisa que una de las especificidades del ‘cronotopo de seguimiento’ es su carácter regresivo. El policial es un género que opera retrospectivamente restaurando, mediante el detective, las claves de un texto trunco e incomprendido: el del crimen ${ }^{4}$. Lo que acciona el seguimiento

\footnotetext{
Se deduce de sus palabras. Bajtín habla de la "novela policiaca de aventuras" como de una estructura dependiente de "pesquisas, huellas de los crímenes y reconstrucción de los acontecimientos por medio de esas huellas" (277).

Es Todorov quien describía el relato enigma-que coincide en varios aspectos con el neopolicial si no nos dejamos sorprender por su dogmatismo sociocrítico-en estos términos: "[E]n la base de la novela enigma se encuentra una dualidad, y es ella quien va a guiarnos para describirla. Esta novela no contiene sino dos historias: la historia del crimen y la de la pesquisa [...] Se trata pues, en la novela enigma, de dos historias de las cuales una está ausente pero es real, la otra presente pero insignificante" (65-67). Ricardo Piglia, en Formas breves, en el ensayo "Tesis sobre el cuento" formula una idea similar que, extrapolada al relato policial, redunda en el papel central que el género desempeña en la propuesta pigliana. Según Piglia, el cuento, y eso es particularmente evidente en el relato enigma, formula dos historias: la historia 1, o relato de la investigación, y la historia 2, o relato del crimen. La primera permite
} 
es un "no saber", una presencia ausente que, para Piglia, es delimitadora de los mecanismos narratológicos del género: "me parece que una clave de la forma [policial] es que el narrador en primera persona se relaciona con una historia que no es la de él y trata de entender" (Hernández-Castellanos et al. 218). La constatación de que algo no se comprende del todo, de una sombra que irrumpe y perturba intensamente el orden vigente, de un texto elidido y licuado en una multiplicidad caótica de rastros e indicios, y de cuya restauración depende el pacto social, pone en juego tres dimensiones que se concretan en el cronotopo de seguimiento: una dimensión política, otra hermenéutica y otra epistémica. Matizo uno de esos tres aspectos. Aunque la difusión de ideas políticas, como señala Vázquez de Parga, no sea el principal móvil de las novelas policiales, estos textos reproducen "los principios ideológicos que rigen la sociedad de la que nace, además de los propios y particulares del autor" (17). Revalidan, en algún aspecto, esa otra "ficción criminal" (Piglia, Crítica 24), que el poder y sus engranajes ponen en circulación. El relato policial desempeña, por tanto, una función de conservación fundada en la identificación de una relación fuerte entre literatura y estado de derecho.

El cronotopo de seguimiento, bajo su aspecto político, estaría vinculado también al cronotopo del camino, tan importante, según Bajtín, en la narrativa moderna -en la picaresca, el bildungsroman, la novela de aventuras, etc. $-^{5}$. El cronotopo del camino textualiza un encuentro en un espacio en conflicto, en un escenario de intersección entre clases sociales e identidades múltiples, o sea, es el punto de convergencia entre el otro y el mismo; un lugar que facilita el diálogo entre 'tipos' sociales radicalmente diferentes, en este caso, el criminal y el detective, la sociedad y sus márgenes. Es ese lugar ideal que permite interrogar los límites políticos y éticos del mundo desde un afuera, desde una pura exterioridad, como lo es un criminal que pone en jaque el precario equilibrio que sostiene el orden sociopolítico (Martín Cerezo 41).

el desocultamiento de la segunda: "el arte del cuentista consiste en saber cifrar la historia 2 en los intersticios de la historia 1. Un relato visible esconde un relato secreto, narrado de un modo elíptico y fragmentario" (106).

Como señala Bajtín, "el camino es especialmente adecuado para la presentación de un acontecimiento dirigido por la casualidad (pero no solo para tal acontecimiento) [...]. El camino pasa por la novela antigua de costumbres y viajes: el Satiricón, de Petronio, y El asno de oro, de Apuleyo. Al camino salen los héroes de las novelas caballerescas medievales $\mathrm{y}$, frecuentemente, todos los acontecimientos de la novela se desarrollan en el camino o están concentrados en torno al camino (a ambos lados de este)" (394-395). 
Es en ese aspecto que el relato policial nunca me ha parecido una escritura de la totalidad -como la novela realista-, sino de la diferencia.

Dichos cronotopos -el del camino, el de seguimiento y el idílico-pastoril-se imbrican de distintos modos en la tetralogía de Padura. Los cronotopos en el policial y el neopolicial, como concreción plástica de un espacio y un tiempo $\mathrm{y}$, por tanto, de un procedimiento muy singular de búsqueda y detección, adquieren un valor considerable para el encaje de las dinámicas intratextuales. Trataré de explicitar en las líneas que siguen el funcionamiento de las novelas de la tetralogía y los ejes que amparan su organización cronotópica para trazar, en último término, algunas líneas de interpretación que permitan explorar los límites políticos del primer policial de Leonardo Padura.

\section{LOS CRONOTOPOS DE LA TETRALOGÍA DE PADURA: TENSIONES Y PUNTOS DE ENCAJE}

Si bien lo narrado en la tetralogía se sitúa en un tiempo que precede el periodo "especial" cubano (1991-1997), el poder de penetración del autor en el tejido social y su formulación del desencanto revolucionario a través de personajes como Mario Conde, el Flaco, Andrés o Candito el Rojo dotan las primeras novelas neopoliciales ${ }^{6}$ de Padura de un carácter específicamente posthistórico. No hay que obviar, tampoco, que las novelas que integran la tetralogía fueron escritas, en su mayor parte, tras la desintegración del bloque soviético y la difusión de las tesis de Francis Fukuyama sobre el final de la historia con un texto que se hizo célebre y que retomaba los seminarios sobre Hegel impartidos por Alexandre Kojève entre el 33 y el 39 en la École

6 La inscripción de la tetralogía en el espacio genérico del neopolicial, que podría parecer cuestionable, responde, por un lado, al alcance que en Padura adquiere dicha acuñación desde la publicación de su artículo "Modernidad y posmodernidad: la novela policial en Iberoamérica" y, por el otro, a la constatación de que, en lo esencial, el neopolicial de Padura, Paco Ignacio Taibo II, Juan Madrid o Montalbán y la novela negra de Chandler, Ross, James Hadley Chase, etc., comparten una serie de rasgos y temas estables: realismo crítico (no deconstructivo), tematización del estado como generador del crimen y la corrupción, expresionismo estilístico, etc. A lo largo de este artículo matizaré las especificadas de la tetralogía pero dejando entrever que, en su dimensión política, no se aleja en exceso de esas otras propuestas. 
Pratique de Hautes Études de París 7 . Esas novelas, decía, Pasado perfecto (1991), Vientos de cuaresma (1994), Máscaras (1997) o Paisaje de otoño (1998), pertenecen a un periodo político extremadamente complejo, distinto en lo esencial de aquel otro que pudo estimular las narrativas de Carpentier, Cabrera Infante, Severo Sarduy o Reinaldo Arenas.

El diálogo del detective con el pasado revolucionario tendrá lugar en un espacio en ruinas, devastado, en el que restan apenas los despojos del naufragio socialista. El derrumbe del bloque soviético pudo tener alguna resonancia en las primeras novelas de Padura en un contexto en el que los principios de la narrativa policial revolucionaria, que tiene su punto álgido en los años 70 tras el sonado caso Padilla y las purgas ideológicas en el ámbito cultural -y de las que se resienten, especialmente, como testimonia la novela Máscaras, el gremio de actores, directores teatrales y dramaturgos- se revelaron prontamente insuficientes. En un marco en el que el macrorrelato de la negatividad de clases, la esperanza teleológica en el futuro o la fe en las reservas morales del proletariado se hubo agotado, el cronotopo de seguimiento del primer policial revolucionario, cifrado en la mayor parte de casos en un realismo ingenuo e ideológicamente dogmático, pierde su frescura y eficiencia narratológica.

De ahí el giro de Padura a una línea mayormente sociocrítica, dentro, claro está, de unos límites bien precisos, que tiene a sus propios precursores en el hard-boiled estadounidense-Hammett o Chandler-y en el neopolicial de Mempo Giardinelli, Paco Ignacio Taibo II o Vázquez Montalbán. De ahí, también, su modelo "neo" y la modificación cronotópica del género con la que el autor trata de desautomatizar los engranajes del anquilosado policial revolucionario ${ }^{8}$. Valle Ojeda indica, en ese sentido, que Padura es "la puerta y el puente" (196) para una reformulación del género policial cubano. El artículo "Modernidad y postmodernidad: La novela policial en Iberoamérica",

\footnotetext{
Me refiero al artículo “¿El fin de la historia?”, publicado en la revista The National Interest, en el verano de 1988, derivado de una conferencia que el autor impartió en el John M. Olin Center for Inquiry into the Theory and Practice of Democracy en la Universidad de Chicago y que se hizo célebre a principios de los años noventa. Fukuyama describe la llegada del presidente Gorbachov como "un asalto revolucionario a las instituciones y principios más fundamentales del estalinismo y su sustitución por otros principios que per se no son propios del liberalismo, pero cuya única conexión es el liberalismo" (46).

Véase el artículo de Escribà y Sánchez Zapatero "Revolución, desencanto y crítica: la novela criminal en Cuba" (2014) para un listado más exhaustivo de los rasgos del policial revolucionario.
} 
de Padura, da cuenta de esa interrogación sobre los límites del género y de las circunstancias sociopolíticas que propiciaron un cambio de registro:

La novela policial revolucionaria se mantuvo ajena a las innovaciones genéricas que se estaban fraguando en el concierto universal y en el iberoamericano en particular [...]. La crisis editorial, la decadencia del campo socialista, las transformaciones sociales y económicas de la isla, los casos de corrupción en las altas esferas de las Fuerzas Armadas y el Ministerio de Interior, terminaron de dar el golpe de gracia a esta novelística para la que entonces se imponía la necesidad de un cambio de perspectivas como única forma de sobrevivir. Muchos autores han sido incapaces de asimilar el cambio y, en la década del 90 , poco queda de aquella escuela nacida en los 70 y poco nuevo existe de la que debía propiciar la cambiada circunstancia social y cultural del país (Padura, "Modernidad y posmodernidad" 49).

Padura pone el énfasis, sobre todo, en el papel sociocrítico que desempeña esta nueva modalidad discursiva. De lo que se trata es de inscribir el policial en la experiencia de lo cotidiano, en la vivencia de la crisis de los valores, de darle esa plasticidad y dinamismo tan típicamente chandlerianos, y de conectar el relato, según la máxima brechtiana con la que Benjamin clausura la última entrada de su diario de Dinamarca, no "con el buen tiempo pasado [lo utópico], sino con el mal tiempo presente [lo distópico]" (152). El ejercicio de la escritura, para Padura, no será únicamente, como suscribe un lugar común, un acto de rebeldía, sino una cura de la herida que somos en tiempos de crisis a través de una literatura socialmente comprometida que registre la realidad para modificarla. Padura prorroga, en varios aspectos, las tesis lukacsianas en defensa de un realismo crítico (1972); privilegia esos "nuevos realismos" (Noguerol s.p.), alejados de la órbita experimental del boom, que ensayan los escritores de neopolicial. Si la novela policial revolucionaria responde a una lógica histórica y dialéctica en la que lo privado se eleva a lo público a través de la resolución de delitos que cuestionan la estructura política vigente, el neopolicial de Padura interroga los límites de dicha estructura, sus quiebres, y da cuenta de su deterioro y desestabilización generalizada ${ }^{9}$. De ahí la

9 Cabe recordar que Bajtín señala la existencia de un cronotopo de "gran intensidad emotivo-valorativa" (399): el cronotopo del umbral que, según dice, se asocia al momento crítico y a la experiencia de la crisis. El cronotopo del umbral se concreta en los momentos de transición, en los puntos de fractura, en el desamparo que produce el tránsito de lo viejo a lo 
pertinencia de un cronotopo cíclico que permite entretejer el problemático nudo entre un pasado idílico y un presente posthistórico.

La estructura cíclica de la tetralogía, también sus coordenadas cronotópicas, se pone de manifiesto, de entrada, a través de algunos de los peritextos de las obras que integran la serie. Títulos como Vientos de cuaresma y Paisaje de otoño, la segunda y cuarta entrega, se inscriben en una cronología muy precisa que remite explícitamente a la primavera y al otoño, de lo que se deduce otra correlación: Pasado perfecto, la novela que inaugura la tetralogía, textualiza el invierno, el año nuevo, el comienzo de ciclo - de hecho, la novela da comienzo a principios de enero de 1989-; y Máscaras, el verano. Otro peritexto, esta vez una nota del autor en Paisaje de otoño, redunda en dicha asociación entre novelas y estaciones:

Una noche el Conde me susurró al oído algo que, después de pensarlo unos días, terminó por parecerme una buena idea: ¿por qué no hacemos otras novelas? Y decidimos, entonces, escribir otras tres piezas que, unidas a Pasado perfecto (que transcurría en el invierno de 1989, conformaran la tetralogía de "Las cuatro estaciones". Así concebimos Vientos de cuaresma (primavera), Máscaras (verano) y este Paisaje de otoño, cuya redacción concluimos en el otoño de 1997, unos días antes del cumpleaños de Conde y el mío, que por cierto nacimos el mismo día, pero no en el mismo año (Padura, Paisaje 9).

El carácter reiterativo de las estaciones del año reposa en un modelo cíclico en el que el discurrir del tiempo se decide en la regularidad y la repetición. Un esquema así no solo impugna el materialismo histórico y su empuje teleológico, sino que desdibuja y anula la diferenciación entre tiempos. Como indica Paz, en Los hijos del limo, en el tiempo circular, "el remedio contra el cambio y la extinción es la recurrencia: el pasado es un tiempo que reaparece y que nos espera al fin de cada ciclo. El pasado es una edad venidera" (29). Quiero precisar, asimismo, que la circularidad y la condición

nuevo. Es probable que en el neopolicial de Padura el 'cronotopo de seguimiento', aportado por Ibáñez, se interseccione con un cronotopo del umbral derivado de la experiencia de la crisis - presente, también, en Chandler, Montalbán, Paco Ignacio Taibo II, Mario Mendoza, etc.-. La narrativa neopolicial de Padura se instala, de hecho, en ese punto de articulación en el que confluyen crítica y crisis y en el que se solapan, a nivel cronotópico, el eterno retorno - como vivencia derivada del final de la historia- y la incansable búsqueda de un detective que pretende restaurar en el presente el ideal perdido en el pasado. 
posthistórica se entrecruzan en algún punto -en su estatismo, su nostalgia, su desorientación-. La dimensión presentista, asociada al final de la historia, se pone de manifiesto en un individuo desvinculado del pasado y del futuro lo que entraña una suspensión de una 'continuidad histórica'. El último de los hombres, reflexionado por Kojève o por Lipovetsky, vive solo para sí, en un olvido sistemático del otro del pasado y del presente, pues "el sentido histórico ha sido olvidado de la misma manera que los valores y las instituciones sociales" (51). Sin embargo, en el policial de Padura, sigue vigente el empeño utópico del cambio. De ahí la importancia que para el autor adquieren, en el contexto del final de la historia, las tesis de Fukuyama quien, en un gesto netamente retórico en la última parte de su artículo, que no por gratuito es menos sorprendente, se abre a la posibilidad de una historia en movimiento: "siento, y me doy cuenta de que otros a mi alrededor también, una fortísima nostalgia de aquellos tiempos en los que existía la historia [...]. Quien sabe si esta misma perspectiva de siglos de aburrimiento, al final servirá para que la historia vuelva a empezar" $(59)^{10}$.

El final de la historia lleva implícita la agotada promesa de regresar a un movimiento dialéctico signado por la negatividad de clases, o sea, el declive del marxismo y la historia formulada como telos, a principios de los noventa, podría estar vinculado a una vivencia singular del tiempo con una doble dimensión aparentemente antagónica, pero no contradictoria: por un lado, la condición posthistórica, por su estatismo y su cancelación de una espera esencial, remite a los antiguos; por el otro, y por su renovada pretensión de reactivar el tiempo y conciliar el hombre con el movimiento histórico, remite a los modernos. Este problema, reflexionado por Agamben, debe su existencia a la profunda brecha que escinde, específicamente en Occidente, la "eternidad y tiempo lineal continuo" (151). La coexistencia, de gran actualidad, entre la nostalgia por una experiencia revolucionaria de la historia y el resquebrajamiento del mito del progreso ${ }^{11}$ articulan, por tanto, el núcleo de la tetralogía.

10 Matizo que Fukuyama, director delegado del Cuerpo de Planteamiento de Política del Departamento de Estado de los Estados Unidos, readapta, desde la lectura de Kojève, el esquema hegeliano del fin de la historia y lo adecua al marco de intereses del liberalismo estadounidense. Dicha tesis ha sido impugnada e, incluso, actualizada por el propio autor en otras obras como Orden político y decadencia política (2016).

$11 \quad$ Véase al respecto Adiós al progreso (1995) de Antonio Campillo. 
La circularidad de la tetralogía se materializa en una serie de abundantes paralelismos, digresiones, analepsis, resonancias y planos que se repiten de un libro a otro desarticulando la previsible estructura lineal del género o el cronotopo de seguimiento definitorio del relato enigma, la novela negra y el policial revolucionario de primera generación. Estas series, bien trazadas narrativamente, operan como ecos y reminiscencias, y textualizan la inmovilidad de lo narrado y el cansancio de un detective circunscrito en un tiempo sin horizontes. Podríamos tratar de agruparlas, por temática y recurrencia, del siguiente modo: 1) el contexto culinario, tan específico de la literatura cubana, y en el que intervienen regularmente de una novela a la siguiente los mismos comensales -el Flaco, Mario Conde y Josefina- ${ }^{12}$; 2) el contexto etílico, que reproduce las metódicas borracheras del detective y sus correspondientes resacas -en la mejor tradición de la novela negra estadounidense de Hammett o Chandler-; 3) la autoconciencia del cansancio que restringe la actividad literaria de Conde -se habla de un "cansancio infinito" (208) en Máscaras, de la "experiencia generacional" del desencanto y la frustración (Paisaje 26); de las "muchas razones para el cansancio y la nostalgia" (Pasado 151)-; 4) la reproducción de los mismos LP en el cuarto de El Flaco -y, concretamente, la discografía de Creedence que se convierte en el leitmotiv musical de la tetralogía-; 5) la actividad memorialística del detective que traza el idilio en el que reposan sus escasas esperanzas; 6) la reformulación del mito de Sísifo en varios puntos de la novela; y, finalmente, 7) la compra y reposición, por parte del detective, de un pez peleador que denomina siempre del mismo modo: Rufino.

A su vez, existen una serie de elementos que ponen en juego el carácter argumentativo y lineal del tiempo, en la estela más secuenciada y organizada propia del género policial: 1) la resolución de los casos en cada una de las novelas a partir de un modelo narratológico tradicional que impone un cronotopo

12 En la primera novela, Pasado perfecto, se inicia el ciclo de banquetes que recorren la totalidad de la tetralogía. Josefina, en dicha novela, prepara unas malangas hervidas y sazonadas con ajo y perejil, frijoles además de "unos bistecitos de puerco que quedaron de ayer" (Padura, Pasado 30). La segunda novela recoge el intertexto del ajiaco, presente en Fernando Ortiz y Carpentier, definitorio de la cubanidad (Padura, Vientos 65-66) y, en la tercera, esta vez el menú se articula alrededor de un "pavo relleno con congrí" con un sofrito prolijamente documentado (Padura, Máscaras 195). Finalmente, en la cuarta novela, los afanes de la cocinera ya revelan cierto cansancio: "el juicio de los comensales fue unánime: a este arroz le faltan los guisantes verdes" (Padura, Paisaje 21), lo que permite leer el ciclo culinario en clave degradativa. 
de seguimiento -con pesquisas, interrogatorios y resolución de casos-; 2) la conciencia de que todo cae, de la degradación de los valores, que acompaña a los personajes a lo largo de su recorrido; 3 ) pequeños cambios que alteran el aparente equilibrio de las cosas - la salida de Cuba de Andrés, el despido de varios cargos en la Central de policía, entre ellos, el Mayor Rangel; el inicio de la actividad literaria de Conde, etc.-; y, finalmente, 4) el creciente y progresivo abatimiento del detective y sus compañeros.

El cronotopo de seguimiento y el cronotopo del idilio, sin embargo, no están perfectamente sincronizados, sino que se tensionan y superponen a lo largo de la tetralogía. Se dan en un espacio en disputa en el que el presente y el pasado, el cansancio y el idilio, el deterioro y el regreso se enlazan en varios puntos. Su acoplamiento es discontinuo, irregular e imperfecto y su engranaje principal es el detective que recuerda. La vida del detective Mario Conde se mide según estos criterios: por ciclos que se repiten periódicamente y que disgregan los límites entre pasado, presente y futuro; y por la autoconciencia del deterioro y la erosión. El detective es entonces una figura considerablemente cronotópica, pues condensa el pulso entre dos espacios y dos tiempos: por un lado, el de un tiempo en movimiento, erosivo, y el de otro tiempo cíclico que se abre a la posibilidad de un retorno al pasado a través de la memoria; por el otro, el de una Habana en decadencia y otra Habana sublimada en el recuerdo. Si, como aduce Bajtín, las imágenes literarias son imágenes del tiempo, en tanto que no hay representación que no esté inscrita en unas coordenadas espaciotemporales, la figura de Mario Conde representa un tiempo de espera. El detective de la tetralogía es un personaje límite, precario, que se da en el epicentro de esa tensión entre la fatalidad del tiempo cíclico y el sueño utópico del que espera. Planteo una serie de cuestiones al respecto.

La relectura del detective a la luz del mito de Sísifo - que de modo tácito o, en ocasiones, de forma explícita, aparece formulada en estas obras- da algunas claves para la comprensión de dicha imbricación. En los primeros fragmentos de Pasado perfecto, por ejemplo, en el inicio del nuevo año, el detective se descubre bajo el signo de Sísifo: "el timbre del teléfono seguía sonando como ráfagas de ametralladora que perforaban sus oídos y trituraban su cerebro, lacerado en una tortura perfecta, cíclica, sencillamente brutal [el énfasis es mío]" (Padura, Pasado 13). El detective siente el encierro en ese "mal espiritual", en ese exilio forzado de quien no tiene casa, en esa náusea existencialista y en esa "sensibilidad absurda que puede encontrarse dispersa en el siglo" (Camus 11). La imagen de Sísifo es restaurada en la cuarta novela de la serie, Paisaje de otoño, cuando Mario Conde lamenta 
su destino y el de sus amigos atrapados en el infructuoso movimiento de la rueda. Señala Conde que todos ellos, casi todos ellos, viven condenados "al eterno ejercicio de Sísifo: subir para tener que bajar, bajar para tener que subir, sabiendo que nunca se quedaría arriba, cada vez más viejos y más cansados, como subía esa noche, después de haber descendido [el énfasis es mío]" (Padura, Paisaje 69). O sea, la circularidad de Sísifo se solapa con un evidente proceso de deterioro físico y moral en un paradigma espaciotemporal que avanza y en el que se consume la vida. En el punto de articulación entre erosión y repetición, toma forma una de los cuestiones más paradigmáticas de la literatura neopolicial -y de la novela negra estadounidense-, y que, en Padura, adquiere un tono particularmente efectista: el desencanto como formulación irónica de la espera.

La articulación del pasado revolucionario, como una épica colectiva sin claroscuros, es reemplazada, en la tetralogía, por una escritura que tensiona el solipsismo del discurso institucional desde otras microficciones producidas en los márgenes que permiten visibilizar los encajes en los que toman forma la represión, las violencias biopolíticas y el engaño. La experiencia de los marginados por la política cultural y de los críticos con los anacrónicos planes económicos del castrismo cristalizan en ese espacio en ruinas que Mario Conde transita en cada investigación y en el que el presente y el pasado se correlacionan cronotópicamente.

Sin embargo, aunque Padura formule el neopolicial en términos de sociología literaria, como "ejercicio de crítica social" (Padura, "Modernidad y posmodernidad" 50) realizada por militantes mayormente de izquierdas; en la tetralogía se pone de manifiesto una cesura compleja entre ética y epistemología, o sea, entre una postura posmarxista y, en el caso del autor, revisionista; y una epistemología conservadora que aspira a restablecer, en el presente, el proyecto utópico de un pasado que nunca fue, como si no hubiese un afuera del binomio capitalismo-socialismo ${ }^{13}$. Esa sublimación del pasado asimila el gesto político de algunos escritores estadounidenses

13 Es evidente que el cronotopo interno -el espacio y tiempo objetos de representación-, en el caso del neopolicial, está sujeto al cronotopo externo, esto es, al contexto sociopolítico, pues trata de reproducirlo narrativamente para validarlo o impugnarlo. También esta vez son dos cronotopos que se tensionan el uno al otro como señala Bajtín: "La obra y el mundo representado en ella se incorporan al mundo real y lo enriquecen; y el mundo real se incorpora a la obra y al mundo representado en ella, [...] en la reelaboración constante de la obra a través de la percepción creativa de los oyentes lectores" (404). 
de novela negra. El espacio político trazado en los relatos policiales de Chandler o Ross MacDonald define, bajo la falsa apariencia de la rebeldía e incorrección políticas, un conjunto de valores retrógrados, misóginos y pseudofeudales que retoman el modelo de bonanza económica que se vivió en la década de los años veinte en Estados Unidos. Ross MacDonald, por ejemplo, participa de ese doble gesto, específico del neopolicial, en el que se entrecruzan un conato de rebeldía y un convencimiento ideológico sin fisuras que dificulta la interrogación de los límites ideológicos de la macroestructura. Según Giardinelli, MacDonald es uno de esos autores que, como Chandler o Padura, aún cuestionando el orden vigente, "en el fondo creen en él y en su capacidad regenerativa" (137).

Para Padura, en efecto, la literatura cubana, en la isla y en la diáspora, está atravesada por una dimensión política que parece intrínseca al fenómeno cultural cubano -si se dejan de lado casos tan heterodoxos como el de Piñera, Lezama Lima o Eliseo Diego-. Padura retoma en algún punto las tesis del Carpentier de "Papel social del novelista" (1981) que tienen su precedente en las "palabras a los intelectuales" de Fidel Castro, cuyo impacto mediatizaría la agenda cultural cubana en las décadas siguientes. El relato policial revolucionario, del que hablaba anteriormente, se inscribe en esa matriz teórico-ideológica. Padura, por su parte, en su ensayo "Quisiera ser Paul Auster", subraya el desacomodo que lo ideológico produce en todo escritor. Para él las consignas políticas fuerzan, anquilosan o empobrecen el hecho literario, pero a su vez asume al compromiso de una escritura que contribuya a restaurar y validar el legado de la revolución:

A diferencia de Paul Auster, el escritor -es mi caso, y de ahí mi envidia austeriana- empieza a definirse como escritor por el lugar en que resida: dentro o fuera de la isla [...] Lo curioso, sin embargo, es que aun cuando muchas veces quisiera transfigurar en Paul Auster, por el hecho de ser un escritor cubano ese deseo no me compete: la vida de mi país, lo que ocurre en mi país, mis opiniones sobre la sociedad en donde vivo no pueden serme lejanas. La realidad me obliga a lidiar con un tiempo en el cual, como escritor, cargo una responsabilidad ciudadana (Padura, Agua 103-106).

En síntesis, el desencanto político, la pérdida de confianza institucional, el reconocimiento de la fragilidad estatal y su incapacidad para suministrar justicia, o el agotamiento de las macronarrativas asociadas a la modernidad estimulan la obra de Padura, pero a través una escritura que, en el plano formal y político, no produce un cuestionamiento en sentido fuerte. El neopolicial 
de Padura interroga los límites en los que se circunscribe el poder, cuestiona la norma, trastoca sus límites y reconfigura un ethos, facilitando el acceso a unos nuevos códigos de comprensión ( $c f$. Garí Barceló, "Microhistoria del relato policial"). Sin embargo, bajo ningún concepto se cuestiona la legitimidad de las estructuras vigentes, solo se registran sus carencias, sus rasgos perfectibles. El neopolicial paduriano se identifica, entonces, con una matriz reformista más conservadora de lo que a priori podría parecer, pues su propósito no es violentar los cimientos del orden, sino prorrogar su existencia corrigiendo sus excesos. Su negatividad es, por decirlo de algún modo, laxa en la línea de las tesis posmarxistas de Ernesto Laclau, Chantal Mouffe o Rancière ${ }^{14}$. El neopolicial de Padura, según lo dicho, puede ser pensado como oxímoron: lo que el texto dice y lo que el texto hace -el significado y el significante- se entretejen en un nudo problemático, difícil de deshacer, indiciario de los límites políticos y formales del género. La forma impone un sentido y que el neopolicial paduriano renuncie a retorcer las palabras y a exacerbar los códigos impuestos verticalmente convierte su propuesta en un fenómeno formalmente conservador que refuerza axiomáticamente los intereses políticos del régimen.

Frente al utopismo político del policial revolucionario-que recodifica el modelo de pesquisas y seguimiento del relato enigma-, la escritura neopolicial de Padura establece las pautas para un discurso sociocrítico, pero no insurgente, descriptivo, pero no deconstructivo de los códigos impuesetos; que instala su ideal en un pasado áureo. De ahí el papel productor que desempeña la memoria a lo largo de la tetralogía. Bajtín denomina ese relacionarse con el pasado - un gesto, por cierto, genuinamente premoderno-hipérbaton histórico que tuvo una especial significación en el trazamiento del cronotopo de la novela de la antigüedad:

[L]os mitos acerca del paraíso, la Edad de Oro, el siglo heroico, la verdad antigua, las representaciones más tardías del estado natural, los derechos naturales innatos, etc., son expresiones de ese hipérbaton histórico [...] [que] se define por medio de una noción especial del tiempo, principalmente futuro. A costa del futuro se enriquecía el presente, y especialmente el pasado (299).

14 Véase, por ejemplo, La razón populista (2005) de Ernesto Laclau, La paradoja democrática (2003) de Chantal Mouffe, que trata de deshacer las tensiones del eje democracialiberalismo, o Política, policía, democracia (2006) de Rancière. 
En Padura, como ocurre en el constructo del estado de la naturaleza de Rousseau, el cronotopo se articula en ese eje conflictivo en el que se correlacionan pasado y presente, progreso y repetición, utopía y desencanto. La atenuación de fronteras entre el tiempo pasado, presente y futuro, con el único anclaje del espacio, dotan la tetralogía de una ritmicidad circular, abundante en repeticiones, resonancias, anticipaciones y analepsis, en la que el idilio y la memoria despliegan una función organizadora. La novedad, en Padura, es que en dicha circularidad se inscribe también el horizonte del cambio y de un porvenir cargado de potencialidades.

\section{A MODO DE CONCLUSIÓN. EL CICLÓN COMO ORIGEN Y DESAMPARO}

La Tetralogía de las Cuatro Estaciones de Leonardo Padura se inscribe, como he mostrado, en el interior de un conjunto heterogéneo de textos que comparten una estructura circular similar. Dicha circularidad estimula una libertad interrogadora que permite cuestionar y desplazar categorías como 'progreso', 'identidad', 'historia' o 'sujeto' que podrían resultar poco esclarecedoras para delimitar los contornos de la modernidad latinoamericana. Se suspenden ciertos valores de la modernidad porque el reordenamiento del tiempo o su reinserción en un esquema alternativo -en un paradigma espaciotemporal y perceptual sustantivamente distinto- invalida la fuerza explicativa y el valor semántico de dichas categorías.

Frente a la novela bizantina, la novela de caballerías o la picaresca-como las lee Bajtín en su Teoría y estética de la novela (1989)-, o frente al relato policial decimonónico, la novela negra, la novela realista de tesis o el cuento cerrado, esos otros textos ponen en funcionamiento una serie de recursos -analepsis, prolepsis, ecos, repeticiones, etc.- que problematizan el estatuto lineal del tiempo y su despliegue narrativo como estructura secuenciada, cerrada y productora de sentido. La desestabilización de los marcos de la modernidad occidental, previa deconstrucción de ese tiempo progresivo y de esa historia arrojada sin control hacia un futuro incierto -son Benjamin, Metz o Heidegger quienes también la leerán así-, va acompañada de una interrupción del sentido y el valor de verdad asociados a la primera modernidad. Más concretamente, se cuestiona el registro y los distintos regímenes de aparición de lo verdadero en el contexto de una modernidad en la que un sujeto racional es fundamento de valores y conocimiento. 
¡Écue-Yamba-Ó! (1933) o El reino de este mundo (1949) de Carpentier, Viento fuerte (1950) de Miguel Ángel Asturias, Cien años de soledad (1967) de Gabriel García Márquez, Paisaje de otoño (1998) de Padura o El espectáculo del tiempo (2015) de Juan José Becerra, textos con estímulos y estrategias diversas, bien trabajados narrativamente, son algunos de los ejemplos que obedecen a ese otro esquema, circular o "urobórico", en los que se ponen en juego otras problemáticas, impensadas dentro de una esquematización horizontal, como lo son la determinación de la voluntad del sujeto, las limitaciones explicativas del mito del progreso y la revolución, la dimensión contingente de un individuo que, circunscrito en una circularidad infinita, es uno y múltiple, o sea, un solo hombre en acto y todos en potencia, etc.

Lo que me interesa, no obstante, es señalar que todos estos textos comparten con la tetralogía de Padura la imagen-símbolo, específicamente latinoamericana, del ciclón. El ciclón es introducido en la cuarta novela de la tetralogía: "al principio había sido una muesca remota, todavía innombrada en su incipiente escala de depresión tropical [...]; dos días después adquiría la categoría inquietante de perturbación ciclónica" (Padura, Paisaje 13). La potencia de esa imagen se traduce al final de la novela en un gesto doble, aparentemente antitético: por un lado, la irrupción del ciclón textualiza el origen, es un recomenzar, y, por ende, está atravesado de connotaciones que remiten al nacimiento - espacio idílico, no contaminado, cargado de porvenir-; por el otro, representa la clausura del ciclo, su cénit, al que le sigue una destrucción total y sin paliativos en la que se purgan los excesos del mundo que cae. Ese punto de convergencia, que condensa en un solo instante muerte y renacimiento, el calvario y la resurrección, permite observar el todo como conjunto estructurado, como armonía, dotándolo de coherencia y sentido.

Ese momento suele ir asociado también a una catarsis epistémica o a una epifanía en la que el protagonista asume finalmente sus limitaciones y comprende la realidad. Aureliano Babilonia, por ejemplo, reconoce con clarividencia, en las escenas finales de Cien años de soledad, que su camino ha sido cifrado anticipadamente y que la lectura de los pergaminos de Melquíades sella el destino de la estirpe. También Ti Noel, en el último tramo de El reino de este mundo, mientras un ciclón devasta la totalidad de la existencia, comprende que la condición del hombre es su desorientación, su laboriosa e infructuosa lucha por una justicia y una felicidad que permanece siempre en una zona vetada, "más allá de la porción que le ha sido otorgada" (Carpentier, El reino 156), y que no hay revolución que colme las expectativas de nadie o que se realice en una sociedad cerrada, suturada y reconciliada sobre sí. Asimismo, 
Asturias en la novela que preludia la Trilogía bananera, reflexiona sobre ese "viento fuerte" que coincide con el final del ciclo y que, a su vez, anticipa un recomenzar: "la hora del hombre será el «viento fuerte» que de abajo de las entrañas de la tierra alce su voz de reclamo, y exija, y barra con todos nosotros" (118). Finalmente, Juan José Becerra, en El espectáculo del tiempo, relato quebradizo e inestable que traza fragmentariamente la biografía del protagonista Juan Guerra y que distorsiona a lo largo de sus páginas la posibilidad de un orden cronológico o secuencial explicativo, concluye remedando el cierre apocalíptico de Cien años de soledad, esto es, con la furia ciclónica que depura el espacio y lo nutre con las semillas del porvenir:

Como suele decirse para resumir una catástrofe: no quedó nada. Nada que pudiese considerarse entero, que conservara una forma $o$, al menos, la idea de una forma. Todo fue cubierto de pasado y sobre el campo quedó, como única presencia, la belleza de la destrucción total. Era un mundo nuevo de cosas sueltas que no tenían nombre. A las ocho y diez regresó la claridad, y con ella la calma (525).

La figura del ciclón también desempeña un papel vertebrador en la Tetralogía de las Cuatro Estaciones de Padura, en concreto, como decía, en la última parte, Paisaje de otoño, y facilita unas coordenadas a la luz de las cuales es posible repensar el conjunto de las novelas como armonía, como trompe l'oiel o como todo coherente y cerrado circularmente.

Resulta poco menos que ilustrativa la escena que clausura la tetralogía que, parece evidente, duplica e invierte el episodio en abîme con el que se cierra Cien años de soledad. Si Aureliano Buendía cifra en la lectura de los pergaminos de Melquíades las claves para la comprensión de su futuro -y la lectura, en este caso, vaticina la furia ciclónica y la destrucción de la estirpe-, Mario Conde, en la última escena de Paisaje de otoño, se enfrenta al huracán bíblico, al "viento fuerte", a través de la escritura. En síntesis, la lectura, en Cien años de soledad, clausura todos los caminos, mientras que, en la tetralogía, la escritura ampara la memoria de los hombres y atenúa su disolución. Los recuerdos se vuelven un ritual de resurrección: "la devastación había empezado mucho antes, y el huracán solo era el rematador feroz enviado para concretar las condenas ya iniciadas... Quedaría, si acaso, la memoria" (Padura, Paisaje 259).

Esta parece ser la formulación más lograda del detective Mario Conde: la del hombre que retrocede para reparar en el presente los abusos del pasado. La memoria opera como herramienta emancipadora o, como diría Todorov, como 
instrumento transitivo y ejemplar (2000). Mario Conde funda sus esperanzas en un futuro-pasado, en un sueño que se reitera, lo que inscribe la tetralogía en un espacio circular, con edades que se degradan en su interacción mutua, a la espera del renacer de un tiempo dorado.

Para Conde, que habita el espacio entre utopía y desencanto, es posible articular focos de resistencia. La escritura es, para él, el refugio del ser humano, ya que en ella se cifra la extraña posibilidad de reparar el presente e instituir, a través de la memoria, el hogar perdido. Es indudable que todo es recordable, aunque no todo puede ser recordado, pero eso no nos exime del compromiso del recuerdo. Es en ese aspecto que el lenguaje y la memoria, concebidos como amparo y refugio, adquieren en la tetralogía de Padura un carácter salvífico que permite habitar los tiempos de espera.

El círculo se cierra con esa reflexión, con la posibilidad de evocar el pasado y recomponerlo para evitar que se fosilice en una serie de lugares comunes: "el fin del mundo seguía acercándose [reflexiona Conde], pero aún no había llegado, pues quedaba la memoria" (Padura, Paisaje 260). Es un cierre que, como resulta previsible, se identifica con el inicio del ciclo. La novela de Conde, esbozada en las últimas páginas de la tetralogía, se corresponde a la primera novela del ciclo: Pasado perfecto.

\section{BIBLIOGRAFÍA}

Agamben, Giorgio. Infancia e historia. Buenos Aires: Adriana Hidalgo Editora, 2011.

Asturias, Miguel Ángel. Viento fuerte. Buenos Aires: Editorial Losada, 1955.

Bajtín, Mijaíl. Teoría y estética de la novela. Madrid: Taurus, 1989.

Benjamin, Walter. Iluminaciones III. Madrid: Taurus, 1998.

Becerra, Juan José. El espectáculo del tiempo. Barcelona: Candaya, 2016.

Calinescu, Matei. Cinco caras de la modernidad. Modernismo, vanguardia, decadencia, kitsch, posmodernismo. Madrid: Tecnos, 1991.

Campillo, Antonio. Adiós al progreso. Barcelona: Anagrama, 1995.

Camus, Albert. El mito de Sísifo. Madrid: Alianza Editorial, 1995.

Carpentier, Alejo. "Papel social del novelista". La novela latinoamericana en vísperas de un nuevo siglo y otros ensayos. Madrid: Siglo Veintiuno España Editores, 1981. 33-50. El reino de este mundo. Madrid: Alianza Editorial, 2011.

Foucault, Michel. “¿Qué es la Ilustración?”. Actual 28 (1994): 1-28.

Fukuyama, Francis. “¿El fin de la historia?”. Claves de la Razón Práctica 243 (2015): 28-59.

Garí Barceló, Bernat. "Microhistoria del relato policial. Modulaciones políticas del detective latinoamericano". Mitologías hoy: Revista de pensamiento, crítica y estudios literarios latinoamericanos 19 (2019): 341-353. 
Giardinelli, Mempo. El género negro. México: Universidad Autónoma Metropolitana, 1996. Hegel, Georg Wilhelm Friedrich. Fenomenología del espíritu. Madrid: Gredos, 2014.

Hernández-Castellanos, Camilo y Jeff Lawrence. "La ficción paranoica y el nacimiento de la novela policial: una entrevista con Ricardo Piglia". Studies in Latin American Popular Culture 29 (2011): 218-229.

Ibáñez, María Susana. "Variaciones en el policial negro. El deseo de los héroes y la infelicidad en la cultura". Tesis doctoral. Universidad Nacional de Córdoba, Argentina, 2013.

Laclau, Ernesto. La razón populista. Buenos Aires: Fondo de Cultura Económica, 2005.

Lipovetsky, Gilles. La era del vacío. Barcelona: Anagrama, 2000.

Lukács, Georg. “¿Experiencia socialista o naturalismo burocrático?”. Polémica sobre realismo. Coord. Ricardo Piglia. Buenos Aires: Tiempo Contemporáneo, 1972. 9-37.

Martín Cerezo, Ignacio. Poética del relato policial. Murcia: Universidad de Murcia, 2006.

Martín Escribà, Álex y Javier Sánchez Zapatero. "Una mirada al neopolicial latinoamericano: Mempo Giardinelli, Leonardo Padura y Paco Ignacio Taibo II". Anales de literatura hispanoamericana 36 (2007): 49-58.

"Revolución, desencanto y crítica: la novela criminal cubana". Cuadernos de investigación filológica 40 (2014): 171-189.

Mouffe, Chantal. La paradoja democrática. Barcelona: Gedisa, 2003.

Noguerol, Francisca. "Neopolicial latinoamericano. El triunfo del asesino". Ciberletras: revista de crítica literaria y de cultura 15 (2006): s.p.

Padura, Leonardo. "Modernidad y postmodernidad: La novela policial en Iberoamérica". Hispamérica 84 (1999): 37-50.

Paisaje de otoño. Barcelona: Tusquets, 2018.

Pasado perfecto. Barcelona: Tusquets, 2019.

Agua por todas partes, Barcelona: Tusquets, 2019.

Vientos de cuaresma. Barcelona: Tusquets, 2019.

Máscaras. Barcelona: Tusquets, 2017.

Paz, Octavio. Los hijos del limo. Barcelona: Seix Barral, 1986.

Piglia, Ricardo. Formas breves. Barcelona: Anagrama, 2000.

Crítica y ficción. Barcelona: Penguin Random House, 2014.

Rancière, Jacques. Política, policía, democracia. Santiago de Chile: Arcis, 2006.

Todorov, Tzvetan. Los abusos de la memoria. Barcelona: Paidós, 2000.

"Tipología del relato policial". El juego de los cautos. Literatura policial: de Edgar A. Poe a P.D. James. Coord. Daniel Link. Buenos Aires: La Marca, 2003. 63-71.

Valle Ojeda, Amir. "La nueva ciudad cubana (y/o La Habana otra) en la novelística negra de Leonardo Padura". The Detective Fiction of Leonardo Padura Fuentes. Coord. Carlos Uxó. Manchester: Manchester Metropolitan University Press, 2006. 192-199.

Vargas Llosa, Mario. García Márquez: historia de un deicidio. Barcelona-Caracas: Monte Avila Editores, 1971.

Vázquez de Parga, Salvador. De la novela policíaca a la novela negra. Los mitos de la novela criminal. Barcelona: Plaza y Janés Editores, 1986. 